\title{
Franc-maçonnerie et sociétés secrètes contre Napoléon. Naissance de la nation allemande
}

\section{Marita Gilli}

\section{Q OpenEdition \\ 1 Journals}

Édition électronique

URL : https://journals.openedition.org/ahrf/7863

DOI : 10.4000/ahrf.7863

ISSN : 1952-403X

Éditeur :

Armand Colin, Société des études robespierristes

Édition imprimée

Date de publication : 1 décembre 2006

Pagination : 164-167

ISSN : 0003-4436

Référence électronique

Marita Gilli, «Franc-maçonnerie et sociétés secrètes contre Napoléon. Naissance de la nation

allemande », Annales historiques de la Révolution française [En ligne], 346 I Octobre/Décembre 2006, mis en ligne le 10 juillet 2008, consulté le 22 avril 2022. URL : http://journals.openedition.org/ahrf/7863 ;

DOI : https://doi.org/10.4000/ahrf.7863

Ce document a été généré automatiquement le 22 avril 2022.

Tous droits réservés 


\title{
Franc-maçonnerie et sociétés secrètes contre Napoléon. Naissance de la nation allemande
}

\author{
Marita Gilli
}

\section{RÉFÉRENCE}

Gérard Hertault, Abel Douay, Franc-maçonnerie et sociétés secrètes contre Napoléon.

Naissance de la nation allemande, Paris, Nouveau Monde éditions et Fondation Napoléon, 2005, 456 p., ISBN 2-84736-119-7, $26 €$.

1 Les auteurs nous montrent que la gestation de la nation allemande eut largement lieu au sein de sociétés secrètes. Après plus d'un siècle et demi d'incompréhension entre Français et Allemands, ils veulent éviter tout franco-centrisme et tout prussocentrisme afin d'apprécier comment les différences entre nos deux pays font aujourd'hui notre nécessaire complémentarité et notre très grande richesse à l'intérieur de l'Europe.

2 Le prologue affirme la thèse qui sous-tend tout l'ouvrage, à savoir que l'idée de nation allemande s'est imposée après 1806. Nous ne partageons pas tout à fait ce point de vue, estimant qu'il faut remonter plus tôt, ne donnant pour exemple que Görres qui, rentrant de sa mission à Paris où il est arrivé juste après le coup d'État du 18 Brumaire, commence à opposer les nations française et allemande, considérant que les vignobles du Rhin et les oranges du sud ne poussent pas sous le même soleil, et à parler d'une supériorité intellectuelle et morale de l'Allemagne sur la France, lui confiant la mission de réaliser les idées de la Révolution française, tâche que les Français n'ont pas su accomplir. On ne peut pas dire qu'en 1800 le sentiment national n'effleurait personne. Les auteurs sont d'ailleurs bien conscients qu'il faut remonter beaucoup plus loin dans le temps, en particulier à Luther, initiateur de la langue allemande et fondateur de la nation allemande. Ils sont bien conscients aussi, et ils le disent p. 44, que c'est sous 
l'impact de la Révolution française que s'est développé le nationalisme allemand, dans le contexte des succès révolutionnaires dès l'occupation de la rive gauche du Rhin. Mais il est vrai que la défaite de Iena (jugée aussi importante sur le plan psychologique que la bataille de Valmy!), puis celle d'Auerstaedt ont permis une prise de conscience plus générale. Les penseurs et philosophes allemands veulent remuer le royaume de Prusse en profondeur et le rendre capable de vaincre Napoléon. Pour cela, ils font appel à un moyen original, les sociétés secrètes, dont le but a été de venger l'humiliation infligée à Tilsitt et de préparer le peuple à un soulèvement de masse contre la France. Par rapport à d'autres, l'originalité des sociétés de Prusse réside dans deux facteurs : à l'exception de la franc-maçonnerie, elles ont été créées en vue de renverser Napoléon et ont pris naissance dans l'année 1809 et toutes ou presque devaient se dissoudre après avoir atteint leur but. Il est vrai que l'action de ces sociétés qui ont parfois dicté au roi la politique étrangère à suivre et dont les membres se sont investis dans la guerre ont permis de toucher le peuple dans son ensemble, ce qui était moins le cas auparavant.

3 La première partie traite des sociétés secrètes au service de la revanche. Des penseurs tels que Fichte avec ses Discours à la nation allemande (1807-1808), E.M. Arndt, A.W. et F. Schlegel, F.D.E. Schleiermacher avec ses sermons anti-français, H. von Kleist et J. Görres pour ne citer que les plus célèbres sont unanimes à condamner le morcellement de l'Allemagne, source de faiblesse et envisagent déjà une Allemagne unie autour du roi de Prusse devenu empereur. Les manifestes du nationalisme allemand se construisent autour de trois éléments : la langue, la religion et la révolution. L'unité ne pouvait se faire que par une poussée venant d'en bas et c'est là que ces sociétés dont le but était de régénérer le pays et de chasser l'envahisseur ont joué un grand rôle. Les plus importantes ont été la franc-maçonnerie, le Tugendbund (Ligue de la vertu) plutôt de centre gauche, la Gesetzlose Gesellschaft (Société anarchique de Berlin) de centre droit voulant limiter les réformes au strict minimum et le Deutsche Bund (Ligue allemande) très à gauche, composé de républicains ardents et intransigeants. Les loges maçonniques ne prennent pas part directement aux débats, mais ont de nombreux contacts avec les autres sociétés dont l'action ne peut d'ailleurs se manifester que par chacun de leurs membres. La reine Louise a été très en contact avec ces membres qui ne pensaient qu'à la revanche, le roi est plus prudent, car il est très faible. Il y a en fait trois partis à la cour : un parti français favorable à Napoléon, un parti favorable aux vieilles institutions militaires du pays et le parti des amis de la reine. Il eut été intéressant que les auteurs disent un mot de l'attitude de Goethe sur ce sujet. En effet, ce poète était un admirateur de Napoléon qu'il considérait en 1807 « comme une des plus hautes figures qu'ait engendrées l'histoire ». Ayant eu l'occasion de le rencontrer à plusieurs reprises, il déclare en 1808: "Je reconnais volontiers qu'il ne pouvait m'arriver rien de plus haut et de plus réconfortant dans ma vie que de me trouver devant l'empereur français ".

4 La deuxième partie traite des loges maçonniques inspiratrices des sociétés secrètes. Les auteurs rappellent qu'en France, Napoléon protège la franc-maçonnerie pour la rendre dépendante de lui. Ce ne sera pas sans influence sur les pays annexés dont les membres entretiennent avec leurs frères conquérants des liens fraternels. Ainsi, la maçonnerie des territoires annexés pouvait être considérée comme une institution impériale et assujettie à l'Empire français. Ce sont néanmoins trois loges de Königsberg qui sont à l'origine du Tugendbund. D'autres loges participent aux actions de diverses sociétés, mais aussi, par leurs membres, aux divers gouvernements de la Prusse de 1807 à 1815. La décision du roi de Prusse de s'allier avec Napoléon a plongé les francs-maçons dans 
la consternation. L'étude minutieuse des loges montre que, malgré sa position délicate, la franc-maçonnerie a joué, de façon indirecte, un grand rôle dans la lutte contre Napoléon.

5 La troisième partie est consacrée au Tugendbund, créé surtout par des francs-maçons bien que tous ne soient pas d'accord. Malgré l'hostilité de Stein et la double interdiction par Napoléon, puis par le roi en 1809, la ligue survit en travaillant dans la clandestinité et nombre de ses membres sont parvenus aux plus hautes fonctions du royaume. C'est ainsi qu'elle poursuit son but qui est d'aider l'État prussien à lutter contre le mal, à savoir Napoléon, et elle participe aux réformes administratives, économiques et militaires et même aux soulèvements de l'année 1809. La défection de York qui entraîne son pays à briser l'alliance avec Napoléon, à en sceller une avec Alexandre et à entrer dans la guerre permet de voir que les idées du Tugendbund ont fait leur chemin: la défaite de Napoléon forge le ciment de l'unité allemande dans la mesure où l'Allemagne prend conscience des vertus que lui procurerait son unité et se sent déjà invincible.

6 La partie suivante traite de la Gesetzlose Gesellschaft fondée en 1809 et sans statuts, comme son nom l'indique, dont le but était de préparer la Prusse à son avenir après l'avoir libérée par des réformes.

7 Enfin, le Deutsche Bund fondé par Friedrich Jahn prépare à sa façon la guerre de libération. La ligue a deux buts : libérer et libéraliser le pays. Elle désire toucher toutes les classes de la société (sauf la noblesse), développer les idées de Fichte sur le levier puissant que représentait la langue, dispenser aux Allemands une culture commune, participer à la campagne anti-napoléonienne par tous les moyens, créer et animer un réseau d'espionnage, ce qui fut son activité principale. Jahn veut former la jeunesse aux arts martiaux par l'enseignement intensif de la gymnastique et des sports. La grande majorité de ses membres sont des professeurs et ce sont eux qui créeront avec G. de Humboldt l'Université de Berlin. Elle comporte peu de francs-maçons. Elle est à l'origine des corps francs et des Burschenschaften, mais ne peut être tenue pour responsable des déviations qui seront opérées plus tard par le nazisme. Elle a été très surveillée et Jahn est même emprisonné.

8 La partie suivante récapitule les actions communes de ces sociétés. Celles-ci sont de deux ordres. D'abord créer autour de Napoléon une légende noire en préservant les apports de la Révolution française et du siècle des Lumières, mais en déconsidérant le tyran qui les a confisqués à son profit. Les pasteurs ont beaucoup contribué par leurs sermons à cette légende noire; poètes et pamphlétaires également dont les plus célèbres sont Achim von Arnim, Adam Müller, Heinrich von Kleist, Friedrich de la Motte Fouqué, Joseph Görres, Ernst Moritz Arndt... Ensuite, passer à des actions susceptibles de gêner la France: désertions, sabotages, nombreux projets d'attentat contre Napoléon. Les corps francs menés par Lutzow ont joué là un rôle important et leur étendard noir-rouge-or est à l'origine du drapeau allemand.

9 Enfin, une partie est consacrée aux sociétés secrètes prussiennes vues par les principaux pays d'Europe. Les auteurs constatent que les Français les ont considérées avec beaucoup d'indifférence, voire de moquerie.

10 Les auteurs concluent que, depuis Iéna et Auerstaedt, l'abîme créé entre la Prusse et la France est devenu immense. L'empereur disparu, la vindicte des Prussiens s'est reportée sur les Français eux-mêmes. Dans les guerres qui suivent, une part importante est prise par les descendants des membres des sociétés secrètes jusqu'à la seconde guerre mondiale. Il est dommage que, dans cette conclusion, aucune allusion ne soit 
faite au courant progressiste qui perdure après la Révolution française et mènera à la fête de Hambach en 1830 et à la Révolution de 1848.

11 L'ouvrage qui est extrêmement documenté est complété par plusieurs annexes : la liste des membres de la loge Jean aux trois couronnes, celle de la loge Jean à la tête de mort, de la loge Jean au phénix, de la loge de campagne Frédéric pour l'amour de la patrie, la liste des nobles, membres du Tugendbund et des francs-maçons d'autres loges, la liste de quelques membres éminents d'autres loges, la liste des membres du Tugendbund, celle des membres de la Gesetzlose Gesellschaft, la liste des membres du Deutsche Bund, ainsi que des extraits de la constitution du Tugendbund. Sources et bibliographie constituent un instrument de travail très important et, enfin, un index des noms de personnes vient compléter cet appareil critique. Ainsi, l'ouvrage éclaire une partie de l'histoire allemande restée dans l'ombre et apporte, malgré sa thèse unilatérale, une vision enrichissante de l'Allemagne après la Révolution française. 